Espacio y Desarrollo No 33, 2019, pp. 29-45 (ISSN 1016-9148)

https://doi.org/10.18800/espacioydesarrollo.201901.002

\title{
CONSTRUCCIÓN SOCIAL DEL TERRITORIO: PUEBLOS ORIGINARIOS, ESTADO Y GRAN CAPITAL EXTRACTIVISTA
}

\author{
Martha Rodriguez Achung* \\ Pontificia Universidad Católica del Perú \\ mrodrig@pucp.pe
}

Fecha de recepción: 24 de mayo 2019

Fecha de aceptación: 4 de junio 2019

\section{RESUMEN}

El derecho al reconocimiento de territorios indígenas es una demanda de larga data de las poblaciones originarias. Sin embargo, procesos políticos y económicos asociados en su mayoría a períodos de alto dinamismo de extracción de recursos naturales (el más significativo fue el período del boom cauchero de fines del siglo XIX y principios del XX) actuaron a contracorriente de la posesión de estos territorios ancestrales. La reconstrucción de la identidad territorial y cultural ha sido y es parte de un largo proceso de construcción de su agencia social por parte de estas poblaciones. El caso de la creación del distrito de Megantoni (2016), en la región Cusco del Perú, muestra un largo proceso de ocupación y construcción social en una parte del ancestral territorio matsigenka, en el Bajo Urubamba. Su característica principal es la de tener una mayoría absoluta de población originaria (cerca de ocho mil habitantes). Es un territorio caracterizado por su alta biodiversidad y por contar en el subsuelo con importantes yacimientos sedimentarios de gas, lo que lo hace un espacio de confluencia de actores e intereses diversos. Lograr el reconocimiento del área como distrito puede ser también una forma de resistencia a la presencia del capital extractivista. Para la población matsigenka que ha accedido al gobierno distrital, implica un nuevo desafío en este largo caminar de construir su territorio con identidad propia.

Palabras clave: territorio, espacio social, pueblos indígenas, matsigenkas, Megantoni.

* Doctora en Ciencias Sociales (Desarrollo-Población-Medio Ambiente) por la Universidad Católica de Lovaina, Bélgica. Profesora principal del Departamento de Ciencias Sociales de la Pontificia Universidad Católica del Perú. 


\section{Social construction of the territory: native peoples, State and large extractive capital}

\section{Abstract}

The right to recognition of indigenous territories is a long-standing demand of the original populations. However, political and economic processes mostly associated with periods of high dynamism of extraction of natural resources (the most significant was the period of the rubber boom of the late nineteenth and early twentieth centuries) acted against the current possession of these ancestral territories. The reconstruction of territorial and cultural identity has been and is part of a long process of building their social agency by these populations. The case of the creation of the Megantoni district (2016), in the Cusco region of Peru, shows a long process of occupation and social construction in a part of the ancestral matsigenka territory, Lower Urubamba. Its main characteristic is to have an absolute majority of the original population (about eight thousand inhabitants). It is a territory characterized by its high biodiversity and for having important sedimentary gas deposits in the subsoil, which makes this a confluence space for diverse actors and interests. Achieving recognition of the area as a district can also be a form of resistance to the presence of extractive capital. For the matsigenka population that has accessed the district government, it implies a new challenge in this long walk of building their territory with their own identity.

Keywords: Territory, social space, indigenous peoples, matsigenkas, Megantoni.

\section{INTRODUCCIÓN $^{1}$}

Comprender la construcción del espacio social desde un enfoque territorial remite a las lógicas de acción guiadas por intereses y que configuran el proceso de construcción del espacio y el territorio. Entendemos el espacio social como el campo de juego donde interactúan los actores y el espacio físico biológico donde se materializan esos intereses, es decir, el campo en donde interactúan tres elementos centrales: el reconocimiento de derechos, el acceso a los recursos y la expansión de las capacidades. Se trata de tres elementos mediados por el poder actuar y el poder hacer de los actores².

Este artículo trata sobre el proceso de construcción social del espacio y del territorio en el Bajo Urubamba (Cusco, Perú), territorio ancestral del pueblo matsigenka, de la familia etnolingüística arahuaca ${ }^{3}$. En este espacio, confluyen diversos grupos sociales y

\footnotetext{
1 Este artículo es una versión revisada de la ponencia presentada en el X Congreso de la Asociación Latinoamericana de Sociología Rural (Alasru), realizada en Montevideo, Uruguay, del 25 al 28 de noviembre de 2018. 2 A partir del enfoque de Amartya Sen, Gonzales de Olarte (1997) planteó esta primera asociación y, posteriormente, Rodríguez Achung (2005) incluyó, sobre la base de Sen y Hanna Arendt, la dimensión del poder (poder actuar y poder hacer).

3 Los matsigenkas, junto con los amuesha, ashaninkas, no matsigenkas, culina, chamicuro, yine-yami (piros), kugapakori y mashco piro, forman parte de la gran familia etnolingüística arahuaca, a su vez una de las trece existentes en la Amazonía peruana.
} 
económicos, unos caracterizados por economías no capitalistas - de autoconsumo-y otros portadores de alta tecnología en la lógica del gran capital extractivista de recursos naturales, que, desde hace un cuarto de siglo, mantienen permanente relación y negociación por el uso de un territorio que pertenece a pueblos originarios y está dotado de una alta biodiversidad de especies de fauna y flora. Es un territorio actual del novísimo distrito de Megantoni y uno de los que cuentan con mayores recursos financieros para su gestión administrativa.

Nuestra indagación gira en torno a las siguientes preguntas: ¿cuáles han sido los actores, sus intereses y las interacciones entre ellos que han venido configurando el espacio social y ambiental en el Bajo Urubamba, territorio ancestral del pueblo matsigenka?, ¿qué hace posible la convivencia de agentes sociales, económicos y culturales opuestos y disímiles? y ¿es posible un desarrollo territorial sostenible con identidad?

\section{a. El territorio matsigenka en sus orígenes: de la dispersión a la nuclearización y sedentarismo}

Varios estudios coinciden en señalar que el origen del pueblo matsigenka se remonta, por lo menos, cinco mil años antes de nuestra era. Es un pueblo milenario y precolombino que no fue conquistado por los incas. Su alta movilidad espacial hizo que su territorio sea amplio. Abarca un espacio entre varias cuencas hidrográficas: el Alto Manu al este y el río Madre de Dios al sur; y pasando el Vilcabamba, llegaron a los ríos Ene y Apurímac hacia el oeste, y al río Mishagua — que desemboca en el Urubamba (el gran río Eni para el pueblo matsigenka) — hacia el norte (Rodríguez Achung, 2016, p. 6). Este territorio coincide en parte con el actual distrito de Megantoni, creado recientemente, el 6 de mayo de 2016, con una superficie de aproximadamente $10000 \mathrm{~km}^{2}$, menos de la mitad de lo que fue su territorio ancestral.

Las historias de las familias matsigenkas de las comunidades del Bajo Urubamba remiten que, hasta mediados del siglo pasado aproximadamente, vivían aislados y de manera dispersa en grupos familiares cerca de las quebradas, lejos de los grandes ríos, aunque el Eni (el Urubamba) es considerado en la tradición de este pueblo el río más importante. Los intercambios realizados desde tiempos remotos, antes de la llegada de los españoles, por los yines o piros del Alto Ucayali con los quechuas del Alto Urubamba y Cusco implicaron a los matsigenkas del Urubamba. Ya durante la época del caucho (fines del siglo XIX y principios del XX), los matsigenkas eran usados para abastecer de mano de obra a los fundos caucheros, lo cual amplió y profundizó la forma de asentamientos aislados, puesto que los matsigenkas, para protegerse, se aislaron cada vez más de las rutas fluviales principales, viviendo de la caza, la pesca y la recolección (Rodríguez Achung, 2016, p. 7). 
Varios hechos incentivaron a los matsigenkas a desplazarse hacia el gran río Eni (el Urubamba): las guerras intertribales, la creación de escuelas por parte de dos grupos religiosos (la misiones católicas desde fines del siglo XIX y la labor del Instituto Lingüístico de Verano [ILV] entre 1950 y 1970), la seguridad de que no serían raptados (la época del caucho había terminado), la búsqueda de tierras y bosques ricos en fauna, y la posibilidad de encontrarse con otras familias de la misma lengua (arahuaca). De todos ellos, la creación de las escuelas en los años setenta del siglo pasado fue el factor más relevante de atracción hacia esta parte de su territorio.

El territorio original matsigenka abarcaba varias cuencas de esta parte del sudeste de la Amazonía peruana, pero se ha visto reducido debido a la ocupación de sus tierras por población inmigrante andina, particularmente en la parte alta del río Urubamba. Este proceso de ocupación andina encontró un obstáculo en la configuración geográfica y el poco desarrollo tecnológico para superar las caídas de agua del pongo de Mainique, de tal manera que la zona del Bajo Urubamba quedó casi aislada del mercado y la sociedad nacional. La ausencia de carreteras de conexión interna y de vías que lo conecten con el resto del país fue una de las condiciones que permitieron la continuidad de la vida y cultura de este pueblo originario, cuya seguridad alimentaria depende, fundamentalmente, de los recursos que obtiene del bosque y que está vinculado con uno de los más ricos espacios de biodiversidad del mundo (hotspots).

Figura 1. Territorio y desplazamientos hacia el Bajo Urubamba

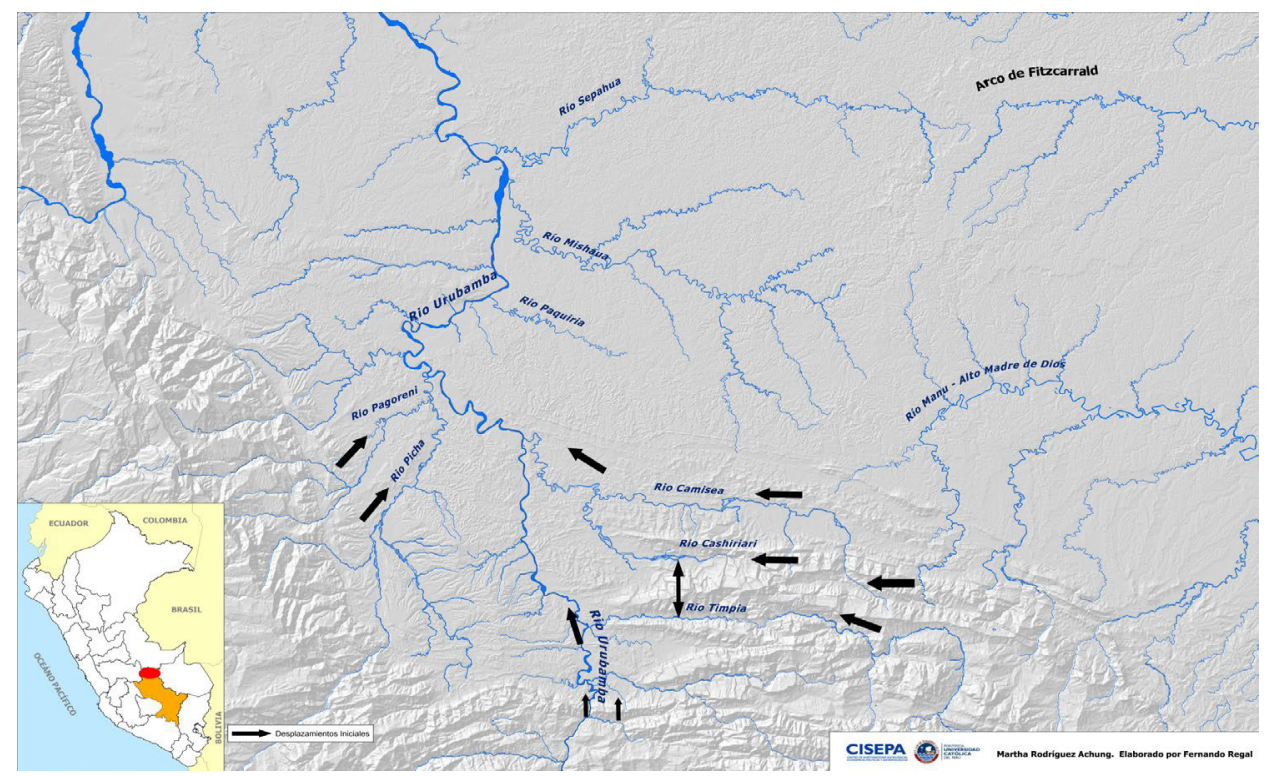

Fuente: Datos de investigación de Martha Rodríguez Achung (Cisepa-PUCP). Elaborado por Fernando Regal, 2016. 


\section{b. Las características socioambientales del área}

Este proceso de ocupación y asentamiento de las familias matsigenkas en el Bajo Urubamba se consolida luego con la creación de las comunidades nativas a partir de los años setenta del siglo pasado. Son núcleos de familias extensas, con población de doscientas a cuatrocientas personas; en la actualidad, suman un total aproximado de ocho mil habitantes ubicados en las riberas del río Urubamba (Eni) y sus tributarios. Sin embargo, las partes altas de las subcuencas continuaron siendo ocupadas por otras familias y clanes en situación de relativo aislamiento. Así, en el alto Camisea, a mediados de los noventa del siglo pasado, existían dos centros poblados: Monte Tomi y Marankiato, entre los dos con una población aproximada de cuatrocientas personas de origen nanti, denominados por los matsigenkas como «kugapakori». Y, en la parte media del río Serjali, se creó Santa Rosa de Serjali, actualmente con trescientas cincuenta personas de origen nahua. En los interregnos, es decir, en medio Camisea y alto Serjali, aún hay presencia de población en aislamiento y de contacto inicial (nahuas y nantis). Diversos grupos familiares también se ubican en el medio y alto Cashiriari y Timpía (matsigenkas); de hecho, la presencia de estos grupos dio lugar a la creación, a inicio de los años noventa, de un área de protección de pueblos en aislamiento y no contactados.

En el Bajo Urubamba, también existen cuatro zonas ocupadas, desde los años sesenta del siglo XX, por población inmigrante, colonos andinos, básicamente peones al cuidado de tierras de los propietarios de fundos — en total, unas cien personas-, áreas de menor tamaño que las actuales comunidades nativas.

El territorio matsigenka es parte de la ecorregión sudoeste del Amazonas y de la importante cordillera de Vilcabamba, una de las veinticinco zonas más relevantes del mundo por su megadiversidad. Los estudios sobre la diversidad biológica realizados durante las últimas décadas dan cuenta de esta condición especial del ecosistema subtropical del Bajo Urubamba, sobre todo los resultados del Programa de Monitoreo y Evaluación de la Biodiversidad a cargo del Smithsonian Institute entre 1996 y 1999 , en el contexto de las exploraciones realizadas por la compañía holandesa Shell; y, posteriormente, los del Programa de Monitoreo de Biodiversidad de Camisea (PMB) a partir de 2005, en el contexto del actual Proyecto de Gas de Camisea (PGC) (Sillero et al., 2002). Por su parte, los registros realizados entre 2008 y 2012 sobre la diversidad de la canasta de alimentos obtenidos mediante la caza y la pesca por la población matsigenka muestran altos índices de diversidad de los recursos ictiológicos y de fauna a los que acceden las familias de las comunidades (Rodríguez Achung, 2015). Además, es importante destacar la alta productividad natural del ecosistema y su importancia en la provisión de agua dulce a la cuenca del Amazonas, y, por tanto, su importante rol en las condiciones del cambio climático regional y global. 
Asimismo, la riqueza de su subsuelo ha sido explorada y analizada con objetivos industriales desde los años ochenta del siglo XX. La empresa Shell exploró toda la cuenca del Bajo Urubamba durante el primer quinquenio de esa década y encontró fuentes sedimentarias de gran potencial de gas. Ubicó las locaciones de Mipaya (en territorio de la comunidad nativa de Nuevo Mundo), San Martín (1 y 2), Armihuari y Cashiriari (1 y 2) en lo que actualmente es el territorio de la Reserva Territorial Kugapakori, Nahua, Nanti y otros (RTKNN). Una década después, ubicó los pozos Pagoreni en territorio de la comunidad nativa de Shivankoreni. A fines del siglo pasado la compañía española Repsol también exploró la zona. Ambos proyectos no prosperaron, en ese momento, hacia la fase de explotación. Esta inició, como veremos más adelante, entrando al siglo XXI con otros actores.

Como se puede observar, los dos principales grupos de actores en el área tienen intereses sobre los distintos recursos ubicados en diferentes estratos del gran territorio matsigenka. El interés del gran capital ha estado y está en la riqueza contenida en el subsuelo (cuencas sedimentarias), y no en el suelo ni en la riqueza de la fauna y flora. De acuerdo con la legislación nacional, el subsuelo y sus recursos son propiedad estatal, así como los bosques de protección, aunque el suelo pueda ser de propiedad comunal. Este es un elemento central para analizar la relación entre los actores. Por ello, la disputa, en este caso, no ha girado en torno a uno o varios de los componentes de esta biodiversidad, pero sí al uso y ocupación del espacio y al rol asignado a la población local, es decir, al acceso y uso de parte del territorio. Es en esta dimensión donde podemos encontrar la interacción entre los actores, y cómo esta influye en la construcción social del espacio y el territorio.

\section{c. La constitución de los actores: derechos y capacidades}

Se afirma de manera reiterativa que el Estado peruano es el gran ausente en esta parte del país. Pero, en realidad, ha tenido un rol importante en la configuración del espacio a través de tres tipos de políticas relativas al territorio: la creación de las comunidades nativas; la creación de las áreas de conservación; y la concesión de lotes o blocks de hidrocarburos al capital internacional para suplir necesidades energéticas del país (principalmente de la costa), y de divisas vía la exportación de recursos energéticos. Sin embargo, las políticas de reconocimiento de derechos de los territorios indígenas y de conservación de las áreas protegidas han sido producto de la capacidad de acción y agencia de sectores de la sociedad civil nacional e internacional (organizaciones indígenas y diversas $\mathrm{ONG}$ ). El Estado peruano es signatario de acuerdos y convenios internacionales de cuidado y preservación del medio ambiente (Convenio sobre Diversidad Biológica de 1992), y de protección de los pueblos originarios (Convenio 169 de la OIT sobre pueblos indígenas y tribales en países independientes de 1989, y la Declaración sobre Derechos de los Pueblos Originarios de Naciones Unidas de 2006). 
En el caso de estudio, el proceso de asentamiento en el Bajo Urubamba se consolida con la creación de la comunidad nativa mediante el decreto ley 20653, Ley de Comunidades Nativas y de Promoción Agropecuaria de las Regiones de Selva y Ceja de Selva, del 18 de junio de 1974, dada durante el gobierno militar de Juan Velasco Alvarado. Esta ley fue impulsada por el sector más progresista de ese gobierno y en respuesta a las demandas de las primeras organizaciones indígenas amazónicas ubicadas en la selva central.

La nuclearización de la población en centros poblados en esta parte del país facilitó que tempranamente se emprendiera el camino a la legalización y reconocimiento de las tierras comunales. Las resoluciones de reconocimiento de las comunidades nativas del Bajo Urubamba están fechadas en 1974, aunque la obtención de la resolución de titulación duró una década e incluso varias comunidades continuaron procesos de titulación para ampliar sus territorios hasta fines del siglo pasado. A la par se inicia un largo proceso de "apropiación» de la forma jurídica de "comunidad nativa» por parte de la población: pasaron varias décadas hasta llegar a identificarse con esta forma de organización, que permitió que los individuos y familias de esta zona sean identificados como pertenecientes a una comunidad reconocida.

Casi simultáneamente, se constituyeron también en organizaciones indígenas: en 1975, se crea la Central de Comunidades Nativas Machiguengas (Ceconama) con apoyo del Instituto Lingüístico de Verano, ya presente en la zona desde varias décadas atrás y con influencia directa en varias de estas comunidades; y, en 1988, se crea el Consejo Machiguenga del Río Urubamba (Comaru) por influencia de Cedia, una organización no gubernamental que trabajó en el proceso de titulación de las comunidades nativas. La primera se afilia luego a la Confederación de Nacionalidades Amazónicas del Perú (Conap) y la segunda, con un estatus especial, a la Asociación Interétnica de Desarrollo de la Selva Peruana (Aidesep), ambas organizaciones nacionales. El Comaru también es parte de la organización internacional de la Coordinadora de las Organizaciones Indígenas de la Cuenca Amazónica (Coica). Es decir, se trata de un pueblo con una agencia social basada en diferentes niveles de articulación, organizaciones de base (comunidad y sus autoridades) y federaciones intermedias, pero, además, con afiliaciones a organizaciones nacionales e internacionales. De esta manera, su capacidad de gestión y negociación se ha ido no solo fortaleciendo, sino también ampliándose en un contexto de cada vez mayor globalización y presencia internacional sobre los asuntos y derechos de los pueblos originarios en el mundo.

Con la creación de las comunidades nativas, el Estado peruano tempranamente (en comparación con otros países de la región amazónica, y mucho antes que los convenios internacionales) reconoció, aunque en extensiones limitadas, el derecho a la tierra de los pueblos originarios amazónicos. Así, cuando en esta parte del país se inició la exploración de hidrocarburos, ya el territorio estaba reconocido como un complejo de comunidades nativas y con organizaciones, aunque incipientes. 
Más aún, la presencia del gran capital acelera y afianza el proceso de apropiación cultural y emocional de la comunidad nativa. La comunidad creada como ente jurídico administrativo desde el Estado es apropiada, a lo largo de cuarenta años, por los grupos, los clanes familiares y los individuos, a quienes la comunidad les dota de una identidad, de un sentido de sociedad. Más allá del clan y la familia, les permite «estar juntos», «estar más próximos», «compartir un mismo lugar». Esta situación promueve el sentido de pertenencia a un lugar, delimitado pero finalmente suyo, dentro de la estructura del Estado. Como dicen Bauman y Tester: «Juntos se comprometen unos a otros» (2002, p. 140).

En 1973, el Estado crea el Parque Nacional de Manu ${ }^{4}$ como área de conservación en la categoría de mayor restricción de uso en la zona este del territorio matsigenka, y crea también su área de amortiguamiento. Esta área será luego reconocida como Reserva del Estado a favor de los grupos étnicos kugapakori y nahua en 1990 (resolución ministerial 0046-90-AG/DGRAAR), que son poblaciones en aislamiento y no contactadas; y, posteriormente, en 2003, se elevó a la categoría de Reserva Territorial Kugapakori, Nahua, Nantis y otros - RTKNN - (decreto supremo 028-2003-AG).

Por demanda de las organizaciones indígenas con apoyo de las ONG y organizaciones internacionales de la sociedad civil, se fueron creando otras áreas de conservación: al oeste, la Reserva Comunal Machiguenga (creada en 2003); al sur, el Santuario Nacional Megantoni (creado en 2004), lugar del Tonkini, espacio sagrado en la cultura matsigenka (incluyendo el pongo de Mainique, que separa el Alto Urubamba del Bajo Urubamba y que fue un obstáculo natural para la colonización de esta parte baja). Se configura, entonces, un espacio compuesto por comunidades nativas con linderos continuos, a diferencia de otros espacios amazónicos donde prima la discontinuidad y la fragmentación del territorio de los pueblos originarios. Esta zona, además, se encuentra rodeada de importantes áreas de conservación de la biodiversidad, que forman parte del sistema nacional de áreas protegidas.

Ya con el retorno a la democracia, luego de los años del gobierno reformista militar, y durante la década de 1980, se exploró de manera insistente las posibilidades de encontrar hidrocarburos en la zona del Bajo Urubamba. Dos compañías, Shell y Chevron, exploraron en el área de las recientemente creadas comunidades nativas, pero sin desarrollar sus proyectos. Shell regresa en 1996 con un nuevo contrato con el Estado peruano, pero solo exploró dos años más y se retiró. El Estado firmó luego, a inicios del presente siglo, un contrato por cuarenta años con el Consorcio Camisea para llevar adelante el Proyecto de Gas de Camisea (PGC), que está en explotación con varias plataformas en territorio de las comunidades y también de la RTKNN. Estos estudios iniciales han dado lugar al desarrollo de los pozos de explotación en el área.

\footnotetext{
4 Reconocida luego como Reserva de Biosfera (1977) y Patrimonio de la Humanidad (1987).
} 
Actualmente, operan en el área, en lotes o blocks de demarcación continua superpuestos a territorios de las comunidades nativas y de la RTKNN, el Consorcio Camisea (conformado por Pluspetrol; Hunt Oil Company of Peru LLC, sucursal peruana; SK Energy, sucursal peruana; Tecpetrol del Perú; Repsol Exploración Perú; Sonatrach Perú Corporation SAC) en los lotes 88 (margen derecha del río Urubamba y con un área importante superpuesta a la actual RTKNN) y 56 (margen derecha e izquierda); Repsol en el lote 57 (margen izquierda del Urubamba y hasta el río Tambo); y Petrobras (actualmente operado por la compañía china Corporación Nacional del Petróleo de China, CNPC) en el lote 58 (margen izquierda del río Urubamba). El que actualmente tiene más desarrollo es el PGC del consorcio mencionado, con varias plataformas en territorio de las comunidades indígenas y dos dentro de la RTKNN, con ductos que conectan a la Planta de Malvinas (margen derecha del río) y con el gasoducto que parte de aquí hacia la costa peruana y que atraviesa el territorio de varias comunidades nativas del Alto Urubamba y del Bajo Urubamba, así como comunidades campesinas altoandinas y de la costa central.

Figura 2. Comunidades nativas, áreas de conservación y lotes de hidrocarburos en el Bajo Urubamba

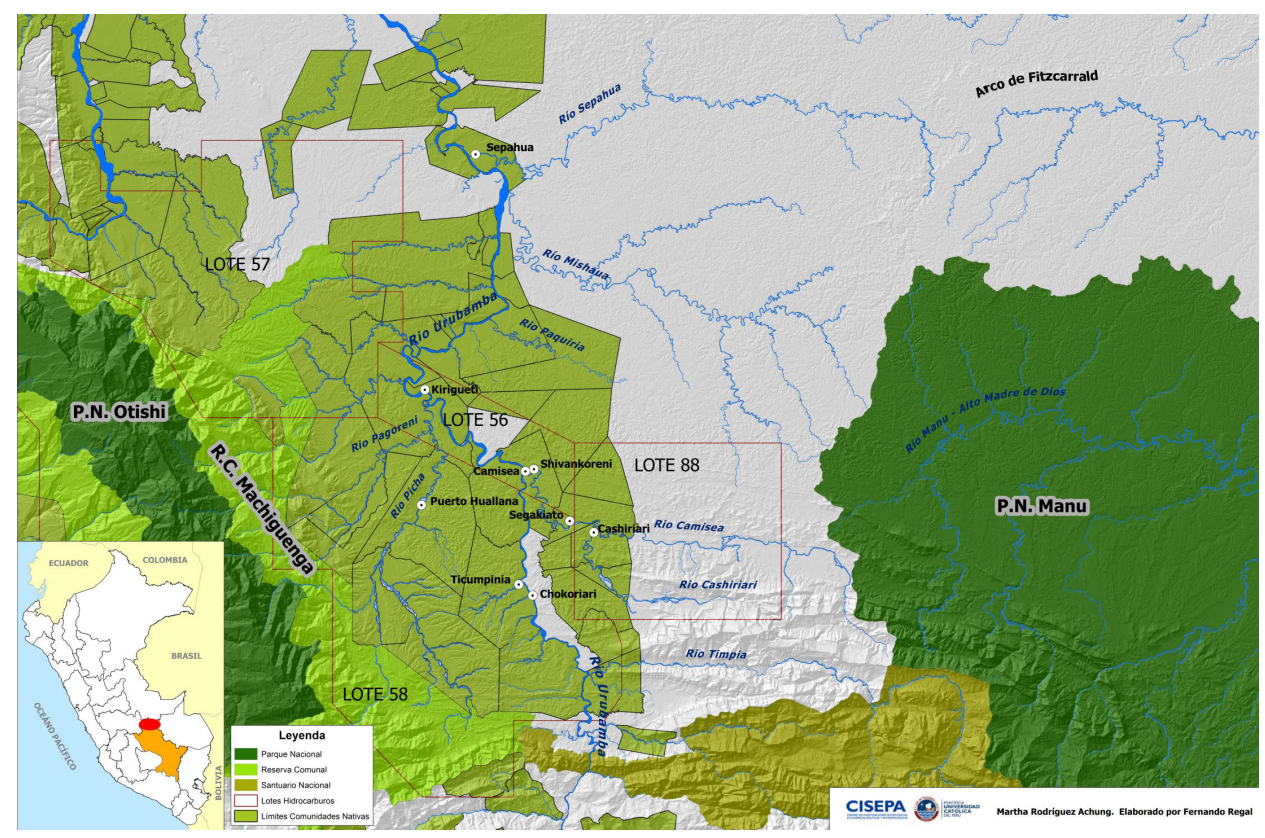

Fuente: Datos de investigación de Martha Rodríguez Achung (Cisepa-PUCP). Elaborado por Fernando Regal (Rodríguez Achung, 2016, p. 27). 
A ello hay que añadir el Proyecto de Gasoducto Sur Peruano, que uniría la planta de producción (en la margen derecha del río Urubamba, distrito de Megantoni) con el sur del país (Cusco, hacia la costa sur). Hoy en día, este proyecto se encuentra paralizado debido al escándalo de corrupción que involucra a la empresa brasileña Odebrecht, que tenía a su cargo esta construcción sobrevaluada (costo que pasó de poco más de 1000 millones a 7200 millones de dólares) $)^{5}$.

La riqueza de este territorio también estuvo puesta en la mira para la explotación del recurso de agua. Empresas brasileñas estuvieron interesadas en su explotación. Con el permiso del Gobierno peruano, la compañía Andrade Gutiérrez obtuvo el 14 de mayo de 2010, por vía del «silencio administrativo», la concesión temporal para construir cinco hidroeléctricas como parte del proyecto energético Mainique, lo que implicaba represar el agua del río Urubamba (Eni) en cinco puntos del pongo de Mainique (espacio sagrado del pueblo Matsigenka, lugar del Tonkini, dentro del Santuario Nacional del Megantoni) (Derecho, Ambiente y Recursos Naturales, 2011). Sin embargo, esta obra no prosperó por la oposición de las organizaciones indígenas y científicas, y de la sociedad civil.

Es decir, se configura un territorio de baja densidad demográfica, con territorios comunales reconocidos en favor de la población originaria, con presencia de población en aislamiento o contacto inicial, con importantes áreas de conservación, y con una expansiva presencia del capital internacional extractivista.

\section{d. La relaciones entre el gran capital extractivista y los pueblos originarios}

Hasta la fecha, la relación entre el capital extractivista (particularmente el megaproyecto de Gas de Camisea) y las comunidades nativas del área ha sido de relativo entendimiento, a diferencia de las tensas y a veces violentas relaciones entre actores similares en la zona norte de la Amazonía peruana. ¿’Por qué ha sido posible este relativo entendimiento?

Una característica del pueblo arahuac y los matsigenka es su aversión a la riña y a la endoguerra (Santos y Barclay, 2004, p. xxviii). Es un pueblo pacifista y colaborador. Por su parte, las compañías, en particular el PGC, tuvieron que someterse a los nuevos estándares exigidos en cumplimiento del respeto por los derechos de los pueblos indígenas, y por las normas nacionales e internacionales de cuidado del ambiente, suscritos además por el Gobierno peruano y cuyo cumplimiento es exigido por la sociedad civil

\footnotetext{
5 Este costo hacía de esta obra la inversión más grande registrada en la historia del Perú. El 23 de enero de 2017, Odebrecht devolvió la concesión al Estado peruano por no encontrar comprador para transferirlo en el contexto del escandaloso proceso de corrupción que envuelve a esta empresa de Brasil y a varios presidentes, funcionarios y personas en el Perú.
} 
tanto al Estado como a la banca internacional que financió parte de la inversión (Banco Interamericano de Desarrollo).

Por otro lado, hubo algunas coincidencias de intereses entre el capital y la población local. Por su parte, la empresa requería mano de obra apropiada para la fase de exploración y para la apertura de pozos y ductos, es decir, mano de obra que tuviera conocimiento del ecosistema, adaptabilidad al clima (humedad, calor, cambios climáticos), seguridad alimentaria para su reproducción, no dependencia del salario para su sobrevivencia y capacidad de retracción a su economía natural.

El capital cuenta, entonces, con un bolsón de reserva de mano de obra a la que puede apelar de manera coyuntural y que no genere problema de desempleo.

En el caso de la población local, dedicada fundamentalmente a la caza, pesca, recolección y horticultura, se beneficiaba por los ingresos monetarios que suponen estos proyectos, el desarrollo de programas de educación y salud, el acceso a la compra de productos industriales, nuevos estilos de vida, y mejora en la infraestructura de la comunidad y en la dotación de servicios. Además, se exigía el mantenimiento de la calidad del ecosistema, particularmente los cuerpos de agua. Esta exigencia es particularmente importante ya que la principal fuente de alimentos y de proteínas de esta población es obtenida mediante la pesca diaria. Con esta, y por tanto con el cuidado del agua, se asegura la subsistencia y reproducción de la vida familiar en el contexto comunal.

La estrategia del pueblo matsigenka en este contexto de relacionamiento ha consistido en lo siguiente:

- Fortalecimiento de las comunidades y sus formas de representación en organizaciones reconocidas por el Estado. De hecho, la representación elegida en asambleas comunales está reconocida legalmente; con ello, se ha logrado el fortalecimiento de las organizaciones intermedias - las federaciones-y sus afiliaciones a organizaciones indígenas nacionales.

- Aumento de su capacidad de negociación para las compensaciones por uso o impacto de las obras sobre sus territorios que provean los recursos para educar a los jóvenes.

- Incremento de la cantidad de trabajo remunerado para los jóvenes y los padres de familia.

- Apropiación de estrategias de conservación de áreas circundantes a sus comunidades: lucha por el reconocimiento de áreas de protección comunal, reservas, santuarios, parques nacionales, etc.

- Obtención de recursos monetarios. Se ha logrado la vinculación con el nuevo mercado de trabajo laboral, pero preservando a la comunidad como refugio y como garantía de su reproducción social, su vida cotidiana, y sus derechos universales, particulares y laborales. 
En relación con la contratación de mano de obra local, dos aspectos son relevantes. El primero es el esquema de relación con las distintas comunidades. La mano de obra es solicitada a las autoridades comunales y es la Asamblea la que designa, de acuerdo con la voluntad de los individuos y familias, quiénes trabajarán en las obras de las empresas, en un esquema de $15 \times 15$, es decir, dos semanas continuas fuera de la comunidad y dos semanas en la comunidad. Este esquema impide que la comunidad y las familias se queden sin varones adultos durante períodos largos. Como se puede observar en la Figura 3, la tendencia de los varones más jóvenes a ausentarse de la comunidad ha ido creciendo; se trata de jóvenes varones que salen a trabajar o a estudiar secundaria y estudios técnicos (financiados mayoritariamente con las compensaciones a las comunidades). El segundo aspecto tiene relación con el hecho de que la contratación de mano de obra foránea no se realiza en la cuenca, y que el personal contratado fuera del área (de Lima principalmente) no puede relacionarse ni estar en el área del centro poblado de las comunidades nativas para evitar el contacto no deseado, aparte de las prohibiciones de cazar, pescar y acceder a los recursos naturales de los bosques. De este modo, desde un inicio, el Proyecto de Gas de Camisea (PGC) controló uno de los conflictos más severos derivados de contactos no deseados con extraños y sus consecuencias ${ }^{6}$.

Figura 3. Tiempo de trabajo remunerado de varones fuera de la comunidad nativa 2009-2012

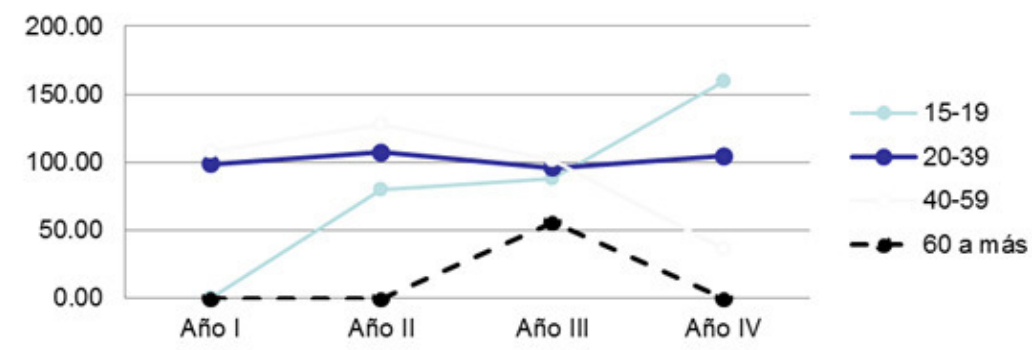

Fuente: Datos de investigación en comunidades de Cashiriari, Shivankoreni y Chokoriari, 2014. Elaboración propia.

Pese a la continua demanda de mano de obra local debido a nuevas exploraciones en el área, la situación de «obrerización» de la población indígena actualmente vinculada directa o indirectamente con los proyectos de hidrocarburos está lejos aún de convertir a sus pobladores en una "clase obrera" o en un grupo que se moviliza por derechos relacionados con esta ocupación. En segundo lugar, y dadas las condiciones y

\footnotetext{
6 El área no tiene conectividad terrestre. Los proyectos gasíferos operan en un modelo offshore, es decir, con acceso aéreo y fluvial.
} 
modelos de contratación de mano de obra indígena, fundamentalmente temporal, no existe posibilidad de crear un grupo unido en torno a la ocupación asalariada temporal que desempeńan. El sentido de pertenencia e identidad radica en la comunidad y su territorio, y sus habilidades para la caza, pesca y recolección junto con la agricultura de subsistencia son la clave para su seguridad alimentaria y su sobrevivencia. Sostiene Miliband: «[...] el "ser social" es en efecto, un conjunto de elementos múltiple y complejo, una especie de ADN social» (1990, p. 440).

\section{e. Territorio: espacio de poder, negociación}

Los actores diversos, por sus intereses, culturas y niveles de organización y representación, y por el contexto en el que se desenvuelven, luego de un período donde solo hubo negociación bilateral (comunidad y empresa, comunidad y Estado, Estado y empresa), fueron creando espacios de negociación desde fines de la década de 1990 e inicios de 2000, año de la firma del nuevo contrato del Proyecto Camisea ${ }^{7}$, hasta la constitución formal del Comité de Gestión para el Desarrollo Sostenible del Bajo Urubamba como asociación civil sin fines de lucro en diciembre de 2012, con el fin de tratar los asuntos de desarrollo de la cuenca, la distribución del canon gasífero ${ }^{8}$ y el impulso a la creación del distrito de Megantoni. A pesar de este avance, las negociaciones continuaron también en la vía bilateral (compensaciones para las comunidades por uso de su territorio; relación entre empresa y comunidad; impuestos, regalías y negociación entre Estado y empresas, etc.). Este comité de gestión estaba conformado por todas la comunidades nativas del Bajo Urubamba, las tres federaciones que las representan (Feconyy, Comaru y Ceconama), cuatro asentamientos de colonos (con presencia mínima pero fuertemente organizados en Cecoabu), algunas ONG (por ejemplo, Cedia, que llevó a cabo, en los años setenta y ochenta del siglo pasado, el proceso de titulación de tierras de las comunidades nativas y viene participando activamente en los estudios para la creación de áreas de conservación en el área), organismos estatales (Ministerio de Energía y Minas a través del Grupo Técnico de Coordinación

\footnotetext{
7 Fue firmado en febrero de 2000 con el consorcio integrado por la compañías Pluspetrol (Argentina, 36\%), Hunt Oil (EE.UU., 36\%), SK Corp (Korea, 18\%) y Tecpetrol (Grupo Techint, Argentina, 10\%) para el derecho de explotar durante cuarenta años el Lote 88 de Camisea. La producción de gas se dedicaría exclusivamente al mercado interno. En 2006, el Estado adjudicó el Lote 56 (con reservas probadas por la exploración de Shell) al mismo consorcio, pero para la exportación de gas, realizada por la compañía Hunt Oil.

8 «El Canon Gasífero, es la participación que perciben las circunscripciones donde está ubicado geográficamente el recurso natural sobre los ingresos que percibe el Estado en la explotación de gas natural y condensados [...] se conforma del 50\% del Impuesto a la Renta, 50\% de las Regalías y $50 \%$ de la participación del Estado en los Contratos de Servicio. El 10\% corresponde directamente a los gobiernos locales distritales» (Ministerio de Economía y Finanzas, 2017).
} 
Intersectorial-GTCI-Camisea), gobiernos locales (municipalidades y gobierno regional), Misión Dominica (entidad católica), Defensoría del Pueblo y las empresas de gas que operan en la zona (Pluspetrol, Transportadora de Gas de Camisea y Repsol —y hasta hace poco Petrobras-).

Frente a las acciones del Comité de Gestión para el Desarrollo Sostenible del Bajo Urubamba, destacan los requerimientos de los colonos ${ }^{9}$ del Bajo Urubamba, y de las organizaciones y actores del Alto Urubamba, donde se encuentra el gobierno distrital de Echarate (el Bajo Urubamba era parte de este distrito hasta antes de la creación del distrito de Megantoni), bajo control permanente de los habitantes de origen andino del Alto Urubamba, en desmedro total de la población originaria.

Tres puntos centrales han sido tratados en este comité de gestión durante los primeros doce años:

- Distribución del canon gasífero. Implicó una negociación con las autoridades del gobierno distrital de Echarate, siempre en manos de población colona sin representación indígena. Parece haber habido coincidencia entre las empresas de gas y las comunidades y sus organizaciones, y también con la representación religiosa - dominicos-, las ONG y los representantes de los colonos. El punto central es qué obras son prioritarias, y dónde y cuándo deben ejecutarse.

- Demandas frente a los cinco derrames del ducto de transporte de gas y compensaciones para las comunidades y familias afectadas. Se trata, básicamente, de un reclamo de las organizaciones indígenas y las ONG. Y se trató, en general, la demanda por la afectación de los cuerpos de agua por el transporte fluvial.

- Creación del distrito de Megantoni. Fue impulsada principalmente por las organizaciones indígenas y las ONG, no por los colonos, pues, con la separación del Bajo Urubamba del distrito de Echarate, este pierde parte de los recursos del canon gasífero bajo el control de los colonos y la población de origen andino.

Los recursos en juego no son pocos. De hecho, el Gobierno de Cusco ha sido uno de los más ricos del país gracias al canon gasífero ${ }^{10}$.

El distrito de Megantoni fue creado, finalmente, en mayo de 2016; pero entró en funciones en 2018. Es un distrito con absoluta mayoría de población originaria y podrá

\footnotetext{
9 Los colonos son inmigrantes andinos en el área y propietarios de fundos dedicados a la ganadería. Ellos se han beneficiado económicamente de manera importante con los proyectos y presencia de las compañías de gas al haberse valorado sus terrenos. De hecho, alquilan sus terrenos para las locaciones de logística de las compañías.

${ }^{10}$ Según información oficial, la región o departamento de Cusco fue la que más recibió por transferencias de canon, regalías, participación y otros entre 2004-2018 (5170 millones de soles), casi el doble del monto transferido a la segunda región con mayor transferencias de este tipo, Áncash, una importante región minera que recibió 2932 millones de soles (Congreso de la República, 2017).
} 
acceder a los recursos del canon gasífero. Se estima que, en 2018, contó con 264,9 millones de soles provenientes del canon gasifero, es decir, un gobierno local con casi igual presupuesto que uno de los distritos más ricos del país (San Isidro, en la capital, tiene 248,7 millones de soles) (Manrique, 2018).

\section{Figura 4. Distrito de Megantoni}

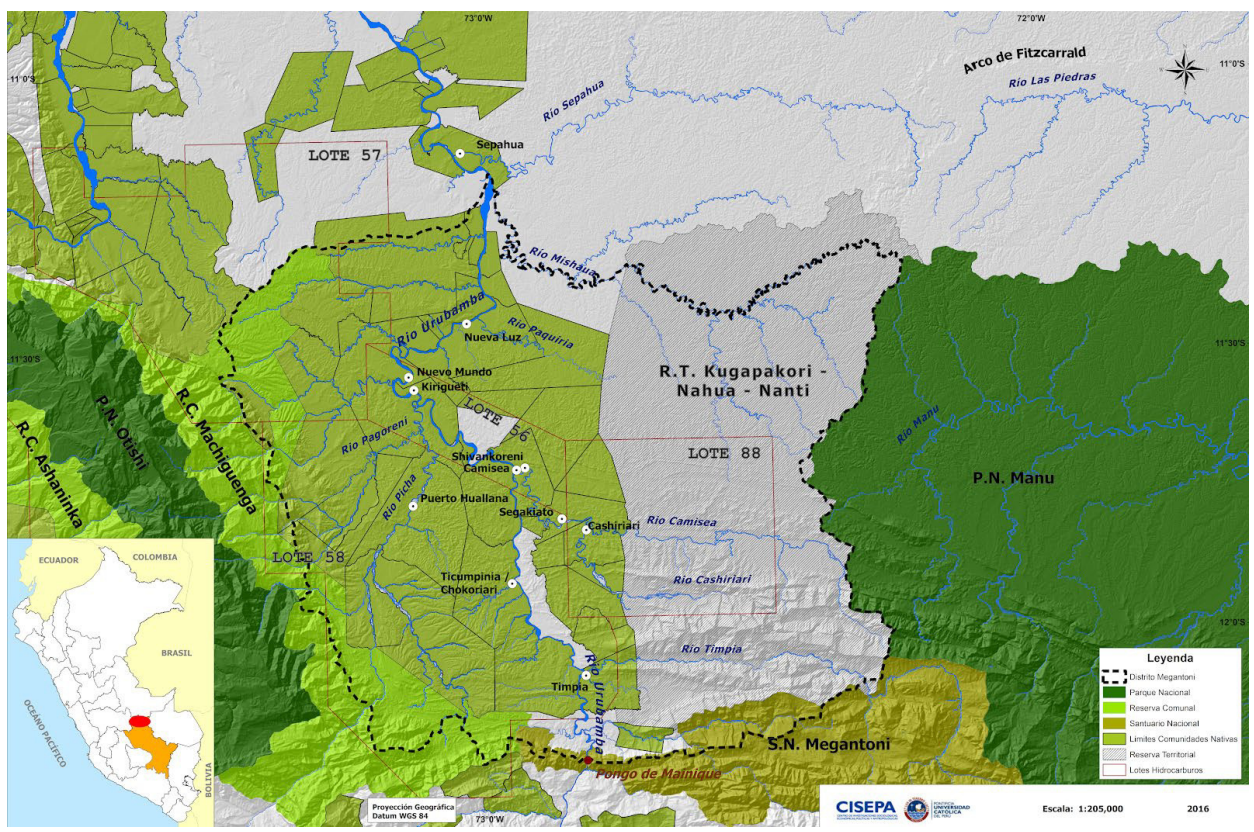

Fuente: Datos de investigación de Martha Rodríguez Achung. Elaborado por Fernando Regal, 2016.

\section{Retos para la gobernanza territorial}

En resumen, el distrito de Megantoni, en el Bajo Urubamba, es un espacio de confluencia de actores, con organizaciones indígenas y líderes con alta capacidad de negociación. Representa a una población local mayoritariamente dedicada a las actividades de caza, pesca, recolección y horticultura, así como a la venta de su fuerza de trabajo temporal al gran capital industrial y financiero. Existen diferentes actores con intereses en el área: el Estado en sus diferentes niveles (central, regional y local), los colonos (pocos pero activos), la iglesia, las ONG (pocas, con presencia física en la zona y más presencia mediática a nivel internacional, tanto proindigenistas como conservacionistas) y las grandes empresas extractivistas de capital internacional. La creación de este distrito se dio en un contexto donde los derechos son reconocidos nacional e internacionalmente, y donde las capacidades de los pueblos originarios se vienen fortaleciendo y expandiendo. Es un espacio, finalmente, donde los principales actores 
no disputan el mismo recurso, aunque sí entran en conflicto y negociación respecto del uso del territorio y la demanda de cuidado del ecosistema, particularmente de los cuerpos de agua.

En este escenario, la creación del distrito de Megantoni es un reto y una oportunidad para que el pueblo matsigenka, avanzando en su constitución como actor social, pueda orientar los recursos según su propia visión de desarrollo. Si bien ha fortalecido su agencia social para la negociación con las empresas y la demanda de derechos frente al Estado, la gestión local requiere no solo capacitarse en habilidades administrativas, sino, y sobre todo, una estrategia de desarrollo sostenible con identidad propia a mediano y largo plazo, en un contexto de afianzamiento de un Estado de corte neoliberal y con grupos de interés que presionan para restringir los derechos territoriales de las comunidades, evitar en lo posible el derecho a la consulta previa (estipulada en el Convenio 169 de la OIT) y ocupar el espacio «sin mucha tramitología», es decir, vulnerando derechos y poniendo en riesgo la propia existencia del pueblo matsigenka.

\section{REFERENCIAS BIBLIOGRÁFICAS}

Bauman, Z. y Tester, K. (2002). La ambivalencia de la modernidad y otras conversaciones. Barcelona, España: Paidós.

Congreso de la República (2017). Transferencias de tipo de canon, regalias, participaciones y otros. Lima, Perú: Congreso de la República. Recuperado de http://www.congreso.gob. pe/Docs/DGP/Comisiones/files/publicaciones/boletintransferenciasportipodecanon.pdf

Derecho, Ambiente y Recursos Naturales (7 de febrero, 2011). Anulan concesión temporal de proyecto hidroeléctrico Mainique 1 [Noticia en página web]. Recuperada de https:// www.dar.org.pe/noticias/anulan-concesion-temporal-de-proyecto-hidroelectricomainique-1/

Gonzales de Olarte, E. (1997). Medio ambiente y pobreza en el Perú. Lima, Perú: Instituto de Estudios Peruanos.

Manrique, L. (6 de agosto, 2018). El canon de Megantoni. El Comercio. Recuperado de https://elcomercio.pe/economia/dia-1/canon-megantoni-noticia-543964

Miliband, R. (1990). Análisis de clases. En A. Giddens (comp.), La teoria social hoy (pp. 418-443). Madrid, España: Alianza Editorial.

Ministerio de Economía y Finanzas (17 de febrero, 2017). Ministerio de Economía y Finanzas [Página web]. Recuperada de https://www.mef.gob.pe/es/?option=com_ content\&view=article\&id $=454$

Rodríguez Achung, M. (2005). Desarrollo, pobreza-exclusión social y manejo de espacios socio ambientales en el mundo rural. El caso del área andina de Perú (Tesis doctoral). Université Catholique de Louvain, Bélgica. 
Rodríguez Achung, M. (2015). Espacios de uso y acceso a la diversidad biológica del pueblo machiguenga del Bajo Urubamba, Cusco, Perú. Revista Geográfica, Instituto Panamericano de Geografía e Historia, 154 (julio-diciembre), 47-63.

Rodríguez Achung, M. (2016). Naro Matsigenka: territorio, comunidad y acceso a los recursos de la biodiversidad. Lima, Perú: Cisepa-PUCP.

Santos, F. y Barclay, F. (eds.). (2004). Guia etnográfica de la alta Amazonía. Volumen IV. Matsigenka / Yánesha. Lima, Perú: Instituto Francés de Estudios Andinos, Smithsonian Tropical Research Institute. https://doi.org/10.4000/books.ifea.8041

Sen, A. (2000). Desarrollo y libertad. Barcelona, España: Planeta.

Sillero, C., Albrechtsen, L., Ferreti, V., Marino, J., Packer, M. J., Palmada, F. M., Rodríguez Achung, M. y Soave, G. E. (2002). Monitoring Biodiversity in Camisea: Scoping Study Report. Buenos Aires, Argentina: Environmental Resources Management. 